Copyright by the Ecological Society of America. Glen N. Stevens and Robert H. Jones 2006 . PATTERNS IN SOIL FERTILITY AND ROOT HERBIVORY INTERACT TO INFLUENCE FINE-ROOT DYNAMICS. ECOlOgY 87:616-624. http://dx.doi.org/10.1890/05-0809

\title{
PATTERNS IN SOIL FERTILITY AND ROOT HERBIVORY INTERACT TO INFLUENCE FINE-ROOT DYNAMICS
}

\author{
GLen N. STEVEnS ${ }^{1}$ AND Robert H. Jones ${ }^{2}$ \\ Department of Biological Sciences, Virginia Polytechnic Institute and State University, Blacksburg, Virginia 24061 USA
}

\begin{abstract}
Fine-scale soil nutrient enrichment typically stimulates root growth, but it may also increase root herbivory, resulting in trade-offs for plant species and potentially influencing carbon cycling patterns. We used root ingrowth cores to investigate the effects of microsite fertility and root herbivory on root biomass in an aggrading upland forest in the coastal plain of South Carolina, USA. Treatments were randomly assigned to cores from a factorial combination of fertilizer and insecticide. Soil, soil fauna, and roots were removed from the cores at the end of the experiment ( $8-9 \mathrm{mo})$, and roots were separated at harvest into three diameter classes. Each diameter class responded differently to fertilizer and insecticide treatments. The finest roots $(<1.0 \mathrm{~mm}$ diameter $)$, which comprised well over half of all root biomass, were the only ones to respond significantly to both treatments, increasing when fertilizer and when insecticide were added (each $P<0.0001$ ), with maximum biomass found where the treatments were combined (interaction term significant, $P$ $<0.001)$. These results suggest that root-feeding insects have a strong influence on root standing crop with stronger herbivore impacts on finer roots and within more fertile microsites. Thus, increased vulnerability to root herbivory is a potentially significant cost of root foraging in nutrient-rich patches.
\end{abstract}

Key words: Elateridae; heterogeneity; root foraging; root ingrowth core; Scarabaeidae.

\section{INTRODUCTION}

Although the relative strength of resource (bottomup) and consumer (top-down) forces on primary producers has long been a central theme in terrestrial ecology (Hairston et al. 1960, Fretwell 1987, Matson and Hunter 1992), integrated studies of their interactions in the soil are rare (Hunter 2001, Moore et al. 2003). The individual influences of soil resource heterogeneity on root density (Drew 1975, Robinson 1994) and of root herbivory on plant succession (Hendrix et al. 1988, Brown and Gange 1990) have been investigated. However, we have little knowledge of how spatial variability in soil fertility acts to structure root-based food webs. Since $50 \%$ or more of ecosystem primary production may be allocated to roots (Jackson et al. 1997), it follows that interactions among resources, roots, and root herbivores can have important implications for both plant communities and ecosystem carbon and nutrient cycles.

Fine-scale (sub-meter) spatial patterns in soil resources elicit foraging responses in plants. Roots tend to proliferate (i.e., forage) in soil patches of increased nutrient availability (Einsmann et al. 1999, Farley and Fitter 1999, Robinson et al. 1999); however, this re-

Manuscript received 24 May 2005; accepted 28 July 2005; final version received 26 September 2005. Corresponding Editor: D. R. Strong.

${ }^{1}$ Present address: Department of Nematology, University of California, Davis, One Shields Avenue, Davis, California 95616 USA.

${ }^{2}$ Author for correspondence (E-mail: rhjones@vt.edu). sponse varies widely among species within a community (Einsmann et al. 1999, Wijesinghe et al. 2001, Rajaniemi and Reynolds 2004). Plants that selectively forage in nutrient-rich microsites can co-opt resources and grow larger than their non-proliferating competitors (Robinson et al. 1999, Hutchings et al. 2003). While foraging may confer benefits to intensively foraging plants, there are costs involved, and a less precise forager may persist in a community at a place or time at which the costs of foraging outweigh the benefits (Fransen and De Kroon 2001, Alpert and Simms 2002).

An overlooked potential cost that may increase with foraging is increased exposure to root herbivory. In natural systems, root herbivores are likely to respond to rich patches, as root-feeding insects can use $\mathrm{CO}_{2}$ concentrations as a primary food source cue (Jones and Coaker 1977, Brown and Gange 1990). Therefore, root herbivore densities should be greater in nutrient-rich areas where roots proliferate and respiration rates are higher (Hogberg et al. 2001). Thus, root herbivores may act in such a way that imparts a significant cost to root-foraging behavior, reducing the net benefit of foraging and influencing competition between plants with different foraging strategies.

Root herbivores may influence not only communityscale interactions (Brown and Gange 1990, Blossey and Hunt-Joshi 2003), but also root life spans, rates of fineroot turnover, and ecosystem carbon cycling. In general, the distribution of root life spans is understood to be strongly left-skewed; many roots live for as little as 1-2 weeks, most live for only a few months, while 
some may live for several years (Matamala et al. 2003, Trumbore and Gaudinski 2003). If herbivores focus on the youngest, finest-diameter roots, which are presumably the most palatable and least defended (Graham 1995, Eissenstat and Yanai 1997) but are also the most critical for resource uptake (Eissenstat and Yanai 1997), root herbivory may be one of the underlying causes of this skewed distribution.

The main objectives of this study were to determine the manner in which root herbivores affect fine-root dynamics within the scale of small patches (microsites) in an aggrading pine-hardwood forest and whether microsite fertility influences the magnitude of root herbivore effects. We installed root ingrowth cores at the beginning of the growing season, amended the cores with fertilizer and insecticide treatments, and returned at the end of the season to measure net fine-root growth and the presence of root herbivores. The data were used to test four hypotheses: (1) suppression of soil fauna would lead to increased fine-root standing crop due to reduced levels of root consumption (root herbivory); (2) the influence of root herbivore suppression would be greater on more fertile microsites (i.e., a fertilizer and insecticide interaction) due to the proliferation response of roots in nutrient-rich patches; (3) changes in root biomass in response to root herbivore suppression should be greater in finer-diameter roots (i.e., those $<1.0 \mathrm{~mm}$ in diameter) compared to coarser roots, since finer roots generally have reduced defenses against and increased risk of herbivory; and (4) root-feeding insect larvae would be more common in fertilized microsites because of preferential herbivore foraging in nutrientor root-rich microsites.

\section{Methods \\ Study site}

Research was conducted at the Savannah River Site (SRS), a National Environmental Research Park administered by the United States Department of Energy and located in the coastal plain of South Carolina, USA. The climate is subtropical with mean July maximum, January minimum, and annual temperatures of $27^{\circ}, 9^{\circ}$, and $24^{\circ} \mathrm{C}$, respectively, and mean annual precipitation of $113 \mathrm{~cm}$ distributed relatively evenly throughout the year (Rogers 1990). Soils at the study site are Dothan and Fuquay series sands (loamy, kaolinitic, thermic Kandiudults; Rogers 1990).

The experiment was conducted during the 2002 growing season in an aggrading dry upland forest harvested in 1995. Prior to harvest, the stand was a 40year-old Pinus elliottii Engl. plantation. After harvest, vegetation was dominated by seedlings of a mix of tree species, including $P$. elliottii, P. palustris Mill., and several Quercus species, as well as a wide range of early successional herbs including various Andropogon, Hypericum, and Rubus sp. (Poaceae, Clusiaceae, and Rosaceae, respectively).

\section{Treatments and response measurements}

Within a $50 \times 50 \mathrm{~m}$ plot, 200 sampling points were established (each representing a sampling microsite) on a $1 \times 1 \mathrm{~m}$ grid. Gridpoint locations for sampling sites were selected by randomly generating $x-y$ coordinates, with the restriction that sampling sites be separated by a minimum of $1.4 \mathrm{~m}$. Microsites were randomly assigned to treatments (50 per treatment) from a $2 \times 2$ factorial combination of \pm fertilizer (Osmocote slow-release 15-9-12 plus minors; Scotts Miracle-Gro, Marysville, Ohio USA) and \pm insecticide (granular chlorpyrifos, Lorsban 15G; Dow AgroSciences, Calgary, Alberta, Canada). Ingrowth cores were installed in March of 2002 at each microsite by first removing a $10 \mathrm{~cm}$ diameter $\times 30 \mathrm{~cm}$ deep core of soil, then extracting the roots by sifting over a mesh sieve, amending the soil according to treatment (5.5 g fertilizer and/or $0.20 \mathrm{~g}$ Lorsban $15 \mathrm{G}$ ), and finally repacking the soil to approximate the original bulk density. Roots removed from each core at the time of installation were returned to the laboratory, separated from residual soil, and divided into fine- and coarse-root fractions $(\leq 2.0$ and $>2.0 \mathrm{~mm}$ diameter, respectively). Root samples were then dried, weighed, and ash-corrected (10 min at $500^{\circ} \mathrm{C}$ ) to estimate microsite ash-free root mass present at treatment installation, a potential covariate that may explain root production within ingrowth cores. Additional insecticide was incorporated into the top 1$2 \mathrm{~cm}$ of each insecticide treatment microsite at approximately 6-wk intervals; during reapplication events all microsite locations were visited and similarly disturbed. Although observations of soil fauna at the time of installation were not recorded, no macro-organisms were observed other than termites (Isoptera), which were associated with woody debris in a limited number $(<10 \%)$ of samples. Woody debris was not returned to the cores when they were repacked.

Twenty-five randomly selected microsites from each of the four treatments were harvested in October and November of 2002 (7 and 8 mo after installation, respectively) by removing a $7.5 \mathrm{~cm}$ diameter $\times 30 \mathrm{~cm}$ deep core centered over the $10 \mathrm{~cm}$ diameter installation location. Soil samples were kept in coolers while transported to the Virginia Polytechnic Institute campus in Blacksburg, Virginia, and stored at $3^{\circ} \mathrm{C}$ until processing. Fine roots and soil insects were removed from the samples by hand washing roots over a 1-mm mesh screen. Washed root samples were separated into three diameter classes $(<1.0 \mathrm{~mm}, 1.0-2.0 \mathrm{~mm}$, and $>2.0$ $\mathrm{mm}$ ) mainly by eye, occasionally verified using dial calipers. Root samples were then dried, weighed, and ash-corrected $\left(10 \mathrm{~min}\right.$ at $\left.500^{\circ} \mathrm{C}\right)$ to determine net production of microsite ash-free dry-root mass (hereafter fine-root biomass) per cubic centimeter in each size class over the period of the experiment. Soil insects from samples were stored in ethanol until identified to family using the keys of Stehr (1987). After identifi- 
cation, insects were dried to a constant mass at $60^{\circ} \mathrm{C}$ and weighed to determine insect biomass.

\section{Test of direct effects of insecticide on plants}

To examine our assumption that insecticide applications would have no direct influence on roots (i.e., insecticide-as-fertilizer effect), we conducted a greenhouse experiment using site-gathered soil and seed of three of the most common perennials at our site (two broad-leaved herbs, Solidago altissima L. and Eupatorium compositifolium Walt., and one grass, Andropogon ternarius Michx.). Plants were grown from seed in $15 \mathrm{~cm}$ diameter $\times 10 \mathrm{~cm}$ deep greenhouse pots in the spring of 2003 (20 pots per species) and allowed to grow for $\sim 4$ mo. Beginning 2 wk after plants were added to pots, $0.20 \mathrm{~g}$ of chlorpyrifos was added to 10 of the pots at similar intervals to that used in the field experiment. At harvest, individual plants were separated into above- and belowground portions. Root samples were separated into $<1.0,1.0-2.0$, and $>2.0 \mathrm{~mm}$ diameter classes. Root and shoot samples were dried to a constant mass and then weighed to determine biomass in each pot.

\section{Statistical analysis}

All statistical comparisons were performed using Statistical Analysis System (SAS) software, version 8.01 (SAS Institute, Cary, North Carolina, USA). Before addressing our hypotheses, we tested several underlying assumptions. First, to test for direct insecticide effects on plants, we used MANOVA (SAS Proc GLM) to analyze the responses of aboveground, belowground (each of three root diameter classes, $<1.0,1.0-2.0$, and $>2.0 \mathrm{~mm}$ ), and total plant biomass of each species to the application of soil insecticide in the single-plant greenhouse pots. Second, to assess the effectiveness of our insecticide applications, we compared insect census data from cores with and without insecticide. Third, potential differences in root and insect responses between October and November harvest dates were assessed using ANOVA.

To test our hypotheses that (1) herbivores had a significant impact on root biomass, (2) this impact increased with increased microsite fertility, and (3) root biomass responses varied between different diameter classes of roots, we compared the fine-root biomass in each of our three root diameter classes $(<1.0,1.0-2.0$, and $>2.0 \mathrm{~mm}$ ) from the four ingrowth core treatments (control, insecticide only, fertilizer only, and insecticide plus fertilizer) using multiple analysis of covariance (MANCOVA) with a $2 \times 2$ factorial design that included root mass in cores at the time of installation (i.e., March 2002) as a covariate, although the covariate was never significant $(P>0.40)$. The data generally did not meet two of the statistical assumptions required for ANOVA (normality and homogeneity of variance), and standard transformations did not result in normality or homogeneity. Therefore, relationships between treatments and root biomass in each diameter class were tested using nonparametric statistics (KruskalWallis, PROC NPAR1WAY). This required combining the two treatments into a single, four-level treatment variable. Significance among these four treatments was assessed using a Kruskal-Wallis test for each diameter class of roots. If the latter test was significant, pairwise comparisons of groups (e.g., individual tests of fertilizer and pesticide effects) were performed using MannWhitney tests. In all cases, the outcomes of the nonparametric tests agreed with the outcomes of parametric ANOVA (at the $\alpha=0.05$ level), and we present only parametric results in this paper. Our fourth hypothesis regarding the presence of insect herbivores in fertilized relative to unfertilized cores was tested using chisquare analysis due to the low occurrence of soil insects. We also analyzed treatment effects on root herbivore biomass using nonparametric ANOVA.

\section{RESULTS}

\section{Insecticide-as-fertilizer and harvest date influences}

In our potted-plant experiment testing for direct effects of the insecticide on plant growth, we observed no direct effects of insecticide on any component of plant biomass (overall insecticide effect, Wilks' lamb$\mathrm{da}=0.96, F_{4,51}=0.52, P=0.72$; see Appendix A for ANOVA table). Although the insecticide did not affect plant biomass, it effectively reduced insect biomass in the field, as we saw no insects in our insecticide-treated cores.

Harvest date did not significantly influence root biomass. The main effect of harvest date $\left(F_{1,191}<2.11\right.$, $P>0.14$ ) and its interaction with fertilizer (all diameter classes $F_{1,191}<2.50, P>0.11$ ) and insecticide (all $F_{1,191}>2.6, P>0.10$ ) were nonsignificant. As a result, harvest dates were combined for all further analyses of root biomass. The proportion of cores with insects did vary significantly between harvest dates $\left(\chi^{2}=\right.$ $11.96, P<0.001)$. Insects occupied cores more often in October than in November (18 cores with insects in October vs. 1 in November).

\section{Effect of treatments on roots}

Fine-root biomass in the smallest size class (i.e., diameter $<1.0 \mathrm{~mm}$ ) ranged from $0.38 \pm 0.037 \mathrm{mg} / \mathrm{cm}^{3}$ (mean $\pm \mathrm{SE}$ ) in control microsites to a maximum of $2.1 \pm 0.15 \mathrm{mg} / \mathrm{cm}^{3}$ in microsites containing both insecticide and fertilizer additions, a more than fivefold difference in root biomass (Fig. 1). Individually, both insecticide applications and fertilizer additions resulted in significantly greater root biomass (nearly two- and threefold increases, respectively) compared to control ingrowth cores $\left(F_{1,195}=47\right.$ and $F_{1,195}=132$, respectively, both $P<0.001$ ); additionally, we saw a significant interaction between fertilizer and insecticide $\left(F_{1,195}=13, P<0.001\right.$; see Appendix B for ANOVA table), a result of a greater positive effect of insecticide 


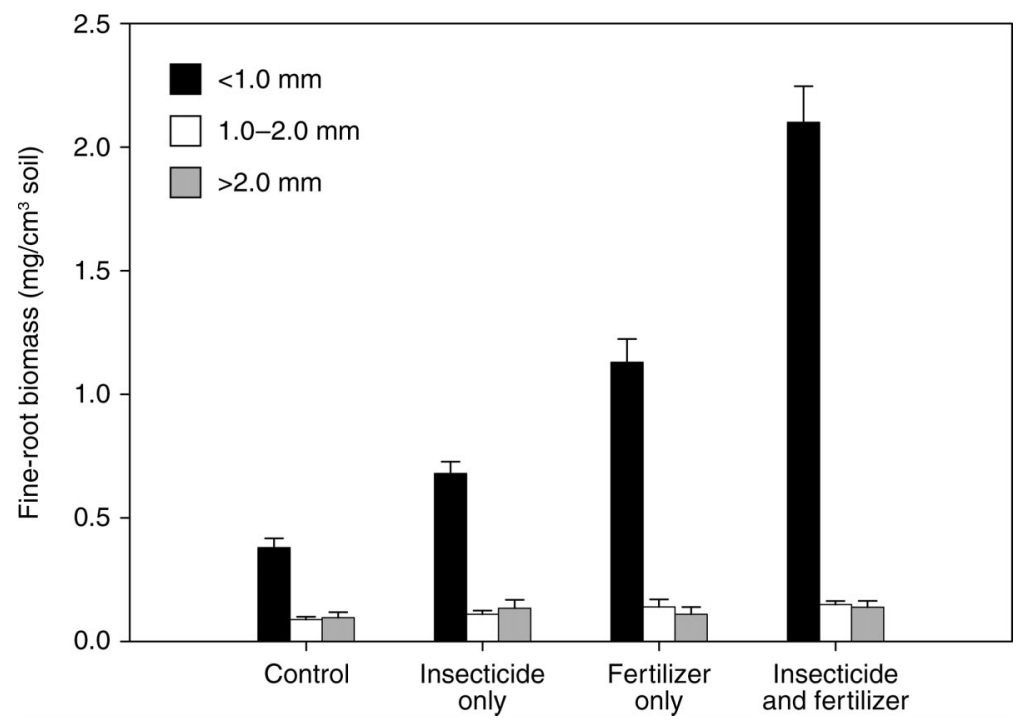

FIG. 1. Insecticide and fertilizer treatment effects on ash-free fine-root biomass production in ingrowth cores (mean + $\mathrm{SE}$ ) in three root diameter classes. Results are from 200 cores, combining results from October and November harvests (harvest effect nonsignificant, $P>0.14$ ). Research was conducted in the Savannah River Site, South Carolina, USA.

application within fertilized than within unfertilized cores (Fig. 1). Together, the two variables (fertilizer and insecticide) and their interaction explained half of the variation in $<0.1 \mathrm{~mm}$ diameter fine-root biomass observed at the time of harvest $\left(R^{2}=0.50\right)$.

Biomass of the two remaining diameter classes of roots $(1.0-2.0$ and $>2.0 \mathrm{~mm})$ was much lower than in the smallest diameter class, and these roots responded to treatments differently than did the finest roots. Midrange roots $(1.0-2.0 \mathrm{~mm})$ had $\sim 1.6$ times more biomass in fertilized than unfertilized cores $(0.088 \pm 0.012 \mathrm{vs}$. $0.14 \pm 0.030 \mathrm{mg} / \mathrm{cm}^{3}$; Fig. 1$)\left(F_{1,195}=5.35, P=0.02\right.$; Appendix B), but did not respond to pesticide application $\left(F_{1,195}=0.50, P=0.48\right.$; Appendix B). Biomass of the coarsest diameter roots $(>2.0 \mathrm{~mm}$ diameter $)$ did not vary significantly in any of our treatments (Appendix B).

\section{Insect response to treatments}

In insecticide-treated cores, we observed no insect adults or larvae. On the other hand, we found insects in 19 of the 100 cores to which insecticide was not applied. Nearly all of the cores with insects contained only a single individual, although two cores contained two (21 insects in all cores). We found representatives from the orders Coleoptera, Diptera, and Blattaria (Table 1). Larvae were found from the families Scarabaeidae and Elateridae (Coleoptera) and Asilidae and Tipulidae (Diptera). We also found adult Scarabaeidae and Carabidae (Coleoptera) and Blattellidae (Blattaria).

Of those insects we observed, larvae from the families Scarabaeidae and Elateridae are well-known root feeders, and some larval Tipulidae feed on roots (Borror et al. 1989). These taxonomic groups represented $76 \%$ (16 of 21) of the insects found in our cores (de-

TABLE 1. Insect data determined from ingrowth cores.

\begin{tabular}{|c|c|c|c|c|c|c|c|c|c|c|}
\hline \multirow[b]{2}{*}{ Order } & \multirow[b]{2}{*}{ Family } & \multicolumn{3}{|c|}{ No. individuals } & \multicolumn{3}{|c|}{ Occurrence $\dagger$} & \multicolumn{3}{|c|}{ Density (larvae/m²) } \\
\hline & & Oct. & Nov. & Total & Oct. & Nov. & Total & Oct. & Nov. & Total \\
\hline \multirow[t]{4}{*}{ Beetles } & Scarabaeidae (larvae) & 10 & 1 & 11 & 0.20 & 0.02 & 0.11 & 45 & 4.5 & 24.8 \\
\hline & Scarabaeidae (adult) & 1 & 0 & 1 & 0.02 & 0 & 0.01 & 4.5 & 0 & 2.3 \\
\hline & Elateridae & 3 & 1 & 4 & 0.06 & 0.02 & 0.04 & 13.4 & 4.5 & 9 \\
\hline & Carabidae & 1 & 0 & 1 & 0.02 & 0 & 0 & 4.5 & 0 & 2.3 \\
\hline \multirow[t]{2}{*}{ Flies } & Asilidae & 2 & 0 & 2 & 0.04 & 0 & 0.02 & 9 & 0 & 4.5 \\
\hline & Tipulidae & 1 & 0 & 1 & 0.02 & 0 & 0.01 & 4.5 & 0 & 2.3 \\
\hline Roaches & Blatellidae & 1 & 0 & 1 & 0.02 & 0 & 0.01 & 4.5 & 0 & 2.3 \\
\hline All root herbivores & & 14 & 2 & 16 & 0.28 & 0.04 & 0.16 & 63.1 & 9 & 36 \\
\hline
\end{tabular}

Notes: As all insects were found in untreated (no insecticide) ingrowth cores, density data are based on untreated cores ( 50 per sampling date, 100 total, each $7.5 \mathrm{~cm}$ diameter $\times 30 \mathrm{~cm}$ deep). Families in boldface italic type represent those with known root-feeding larvae. The research was conducted in the Savannah River Site, South Carolina, USA.

$\dagger$ The proportion of cores containing insects of different families. 
TABLE 2. Root and root herbivore data by fertilizer treatment, considering only cores without pesticide (50 cores per treatment).

\begin{tabular}{|c|c|c|c|c|c|c|c|c|c|}
\hline \multirow[b]{2}{*}{ Treatment } & \multirow[b]{2}{*}{$\begin{array}{l}\text { Root biomass } \\
\left(\mathrm{mg} / \mathrm{cm}^{3}\right)\end{array}$} & \multirow{2}{*}{$\begin{array}{c}\text { Root herbivore } \\
\text { biomass } \\
\left(\mu \mathrm{g} / \mathrm{cm}^{3}\right)\end{array}$} & \multirow[b]{2}{*}{$\begin{array}{c}\text { No. root } \\
\text { herbivores }\end{array}$} & \multicolumn{3}{|c|}{ No. individuals } & \multicolumn{3}{|c|}{ Individual biomass (mg) } \\
\hline & & & & $\begin{array}{l}\text { Elater- } \\
\text { idae }\end{array}$ & $\begin{array}{c}\text { Scarabae- } \\
\text { idae }\end{array}$ & $\begin{array}{l}\text { Tipu- } \\
\text { lidae }\end{array}$ & Elateridae & Scarabaeidae & $\begin{array}{l}\text { Tipu- } \\
\text { lidae }\end{array}$ \\
\hline Control & $0.38(0.037)$ & $0.79(0.56)$ & 5 & 3 & 2 & 0 & $1.67(0.67)$ & $24.50(12.50)$ & 0 \\
\hline Fertilized & $1.12(0.094)$ & $6.6(2.4)$ & 11 & 1 & 9 & 1 & 3.12 & $48.88(10.61)$ & 9.03 \\
\hline
\end{tabular}

tailed results in Table 1). Scarabaeidae larvae (commonly referred to as white grubs) were the dominant root herbivores in our cores.

Root herbivore counts varied between harvest dates, but did not vary significantly between treatments. We saw herbivores in cores more frequently in October (14 insects) than in November (only $2, \chi^{2}=11.9, P<$ 0.001 , Table 1). While we found root herbivores more often in fertilized cores (11 insects) than control cores ( 5 insects) and root herbivore biomass per unit area was eight times higher in fertilized than in unfertilized cores (Table 2), neither occurrence nor biomass were significantly different between treatments.

\section{DISCUSSION}

\section{Root effects}

Results supported our first three hypotheses: root herbivory leads to reduced root biomass, root herbivory is more intense in fertile than in relatively less fertile microsites, and root herbivory was focused on the thinnest diameter roots. To our knowledge, this is the first study that has demonstrated an interaction between root herbivory and fertility. Research on belowground herbivory is generally uncommon (Hunter 2001); however, there is ample evidence that aboveground herbivory, nutrients, and other factors such as producer biomass and natural enemies can interact (Hunter and Price 1992, Hunter et al. 1992). For example, in a study of black locust trees (Robinia pseudoacacia L.), fertilized trees initially suffered higher losses to herbivory, although they eventually appeared to gain some protection due to increases in foliar defenses through secondary compounds (Hargrove et al. 1984). In Spartina marshes, increasing fertility resulted in increased plant growth but also increased herbivore (planthopper) colonization, survival, and fecundity; control by natural enemies was most significant in low-nutrient conditions (Denno et al. 2002). We saw a similar pattern in our study of belowground trophic dynamics, albeit at a much different spatial scale: a positive plant response to increasing fertility that was constrained by increased root herbivory on more fertile sites. Exploring both the responses of the roots themselves to increased root herbivore activity and the responses of the herbivores' natural enemies (including parasitoids such as entomopathogenic nematodes; Strong et al. 1996, Preisser 2003) is the next step in building an understanding of the role of nutrient heterogeneity on root-based food webs.

Although the organophosphate insecticide we used to control soil fauna (chlorpyrifos) may theoretically stimulate production (i.e., act as a fertilizer), neither our greenhouse experiment nor those carried out by other researchers using similar formulations of the same compound have provided evidence of such direct effects on soil fertility (Wells et al. 2002) or on the biomass of plant roots (Coupe 2003) or shoots (Brown and Gange 1989, 1990, Coupe 2003). This supports our assertion that the increase in root mass we observed in insecticide-treated cores was due to a reduction in fineroot herbivory.

\section{Root herbivore responses and life cycles}

While our hypotheses regarding root responses were supported, support for our fourth hypothesis, that root herbivores would be more common on fertilized than "control" microsites, was mixed. Despite the clear influence of insecticide additions on insect biomass, the proportion of samples containing root-feeding larvae was low (only $16 \%$ at the time of harvest). Although we did see higher total numbers of insect larvae in fertilized cores than unfertilized cores, the difference was not statistically significant $(P=0.37)$, leading us to reject this hypothesis.

The incongruity between strong effects on roots and low frequency of root herbivores may have been caused by the timing of our observations relative to the life cycle of the dominant root herbivore we observed (Scarabaeidae larvae, white grubs). White grub root herbivory is generally concentrated into two periods over a growing season. During a given calendar year, the first of these feeding periods occurs in spring, from mid-March to early May; the second occurs between early August and late autumn, at which point the larvae descend to deeper soil horizons $(>30 \mathrm{~cm}$ depth) to overwinter. Given these life history patterns, larvae that fed in the cores may have emerged as adults in early summer or descended beyond our sampling depth by the time of harvest.

Although we did not observe a large number of root herbivores in our samples, our density estimates match up well with those from other studies. In a multiyear study of soil fauna on the Konza prairie, Callaham et al. (2003) observed mean white grub densities of approximately 5 individuals $/ \mathrm{m}^{2}$ and slightly higher av- 
erage elaterid densities; these are much lower numbers than we observed. White grub densities of 46.3 and 47 individuals $/ \mathrm{m}^{2}$ were reported by Ueckert (1979) and Lura and Nyren (1992) in infested areas of shortgrass and mixed-grass prairie, respectively; these densities are nearly equal to those observed in our October samples (45 larvae/m²; Table 1).

In contrast with our density estimates, the rates of occurrence (percentage of samples containing a given taxa) we observed appear low when compared to samples taken near our site: a survey of soil fauna from Calhoun Experimental Forest, located in the South Carolina Piedmont (M. A. Callaham, unpublished data), found Scarabaeidae and Elateridae in a larger percentage of samples $(50 \%$ and $30 \%$, respectively) than we did in this study $(20 \%$ and $6 \%$ for October samples, Table 1). The lower occurrence rates we observed may reflect the reduced size of individual samples in our study $(7.5 \mathrm{~cm}$ diameter cores vs. $30 \times 30 \mathrm{~cm}$ soil pits used by Callaham) or the fact that we sampled late in the year.

\section{Costs and benefits of root foraging}

Our study shows that increased exposure to root herbivores may be a significant cost of root-foraging behavior. This has at least three important implications for interpretation of root-foraging studies. First, it means that laboratory or greenhouse experiments, which usually have little or no root herbivory, probably overestimate benefits for precise foraging in the field and fail to detect important indirect effects that herbivores may have on competitive interactions between plants in natural soil. In our experiment, those plants that foraged heavily in nutrient-rich patches were apparently exposed to higher levels of herbivory than were plants that foraged in areas of lower fertility. Previous studies have shown that fine-root foraging in nutrient-rich microsites significantly influences inter- and intraspecific competition (Robinson et al. 1999, Fransen et al. 2001, Day et al. 2003), but the role that root herbivores may play has been overlooked. Herbivores that forage in rich patches may influence competitive outcomes in plant communities by more strongly affecting aggressively proliferating plant species. Second, increased rates of herbivory in nutrient-rich patches may explain why some field studies have demonstrated a lack of root-foraging precision or have failed to see effects of heterogeneity on growth or competitive interactions in diverse communities (Casper et al. 2000, Bliss et al. 2002). Finally, short-term studies, even if conducted in the field, may be biased if fewer root herbivores exist in the study site than are typical (due to slow movement through the soil, delayed site invasion after soil fumigation, etc.).

The cost imposed by exposure to root herbivory may also impact the evolution of plant root-foraging behavior and the coexistence of species in plant communities. Fine-scale spatial structuring of nutrients, roots, and herbivory may help to explain the range of foraging responses seen even between species with similar adult size and life histories (Einsmann et al. 1999, Bliss et al. 2002, Hodge 2004). Root herbivory may mediate coexistence of species in plant communities, particularly if spatially patchy herbivory suppresses aggressively foraging plants, allowing those plants that forage less precisely (and presumably less efficiently) to persist where they would otherwise be outcompeted.

\section{Implications for carbon cycling belowground}

Root herbivory represents a rapid route of root turnover, one that is congruent with our improving understanding of the predominance of young age classes in root systems. Whereas previous models had assumed a normal distribution of fine-root life spans, the reality appears to be that root life spans are strongly leftskewed (Tierney and Fahey 2002, Trumbore and Gaudinski 2003), with many roots disappearing, due to herbivory or other causes, within weeks to months of "birth" (Stevens et al. 2002, Wells et al. 2002), although some roots may live for as long as nine years (Gaudinski et al. 2001, Matamala et al. 2003). What has been thought of as a large, homogeneous pool of roots is in truth a combination of different pools, more of which turn over more quickly and some of which live much longer than we have previously understood (Pregitzer 2002, Trumbore and Gaudinski 2003).

Root herbivory likely represents a significant cause of fine-root turnover in many terrestrial systems, given the widespread distribution of the herbivores themselves. In the family Scarabaeidae, some 153 species from the genus Phyllophaga have been identified across the United States (Forschler and Gardner 1990), and the Japanese beetle (Popillia japonica) is common to nearly all states east of the Mississippi River (Vittum et al. 1999). The list of potential root herbivores is long and includes (but is not limited to) insects from the orders Lepidoptera, Diptera, and Hymenoptera (reviewed in Brown and Gange 1990) and root-feeding nematodes.

Although this project focused on the responses of roots and soil macrofauna to fine-scale nutrient patches, soil organisms such as plant parasitic nematodes, mites, or Collembola likely also responded to our experimental treatments. Soil biota generally exhibit strong spatial heterogeneity, with many organisms exhibiting patchy distributions at fine (sub-meter) spatial scales (Ettema and Wardle 2002). The mechanisms controlling these distributions are variable and may include oviposition effects, responses to patterns in soil moisture, resource availability, texture, and chemistry, and responses to patterns in plant growth (Ettema and Wardle 2002). In this study, the insecticide we used likely reduced populations of all soil organisms, as chlorpyrifos applications generally result in reduced densities of earthworms (USDA 2001), Collembola 
(Frampton 1999, Pereira et al. 2005), mites (Cabrera et al. 2004, Pereira et al. 2005; but see Michereff-Filho et al. [2004] for contrasting results), and soil arthropods in general (Wang et al. 2001, Dawson et al. 2003, Pereira et al. 2005; but see Clements et al. [1988] for contrasting results for Carabidae). The effect of increasing microsite fertility on soil fauna is more difficult to predict. Although organisms such as plantfeeding nematodes are known to increase in density after fertilization (Smolik and Dodd 1983, Todd 1997), such responses are generally measured at the scale of large field plots and overlook fine-scale effects. In a pot study examining the effects and responses of soil fauna, DeDeyn et al. (2004) observed that the densities of plant parasitic nematodes increased with root biomass and attributed this to bottom-up effects of resource supply on root herbivores. We saw a similar trend in this study, with increased losses to root herbivores in more-fertile patches. Although we limited our assessments of soil fauna to macroarthropods, it is very reasonable to hypothesize that other types of root herbivores responded positively to the increased root biomass available in fertilized patches.

In sum, we have demonstrated that root-feeding fauna can have significant effects on fine-root dynamics (and thereby carbon cycles) that increase with microsite fertility. This suggests that nutrient patterns in the soil may act as a template that structures root-based food webs and further supports the need to consider root herbivores in our models of plant community interactions (Bardgett and Wardle 2003, Moore et al. 2003, DeDeyn et al. 2004) and ecosystem carbon cycling.

\section{ACKNOWLEDGMENTS}

We thank Julia Showalter, Jennifer Lyon, Megan Ward, and Eli Wentz for field and lab assistance and Mac Callaham from the US Forest Service Southern Research Station for making comparison data on soil fauna available. The manuscript was improved by helpful comments from Lynn Adler, Ed Lewis, Maury Valett, Donald Strong, and two anonymous reviewers. Funding for this project was provided by National Science Foundation Grant DEB-0308847, the Virginia Tech Graduate Student Assembly, and the Virginia Tech Department of Biological Sciences. We appreciate the use of the Savannah River Site, a National Environmental Research Park, and the assistance of the USDA Forest Service.

\section{Literature Cited}

Alpert, P., and E. L. Simms. 2002. The relative advantages of plasticity and fixity in different environments: when is it good for a plant to adjust? Evolutionary Ecology 16: 285-297.

Bardgett, R. D., and D. A. Wardle. 2003. Herbivore-mediated linkages between aboveground and belowground communities. Ecology 84:2258-2268.

Bliss, K. M., R. H. Jones, R. J. Mitchell, and P. Mou. 2002. Are competitive interactions influenced by spatial nutrient heterogeneity and root foraging behavior? New Phytologist 154:409-417.

Blossey, B., and T. R. Hunt-Joshi. 2003. Belowground herbivory by insects: influence on plants and aboveground herbivores. Annual Review of Entomology 48:521-547.
Borror, D. J., C. A. Triplehorn, and N. F. Johnson. 1989. An introduction to the study of insects. Sixth edition. Saunders College, Philadelphia, Pennsylvania, USA.

Brown, V. K., and A. C. Gange. 1989. Differential effects of above- and below-ground insect herbivory during early plant succession. Oikos 54:67-76.

Brown, V. K., and A. C. Gange. 1990. Insect herbivory below ground. Advances in Ecological Research 20:1-58.

Cabrera, A. R., A. A. Cloyd, and E. E. Zaborski. 2004. Effects of greenhouse pesticides on the soil-dwelling predatory mite Stratiolealaps scimitus (Acari: Mesostigmata: Laelapidae) under laboratory conditions. Journal of Economic Entomology 97:793-799.

Callaham, M. A., Jr., J. M. Blair, T. C. Todd, D. J. Kitchen, and M. R. Whiles. 2003. Macroinvertebrates in North American tallgrass prairie soils: effects of fire, mowing, and fertilization on density and biomass. Soil Biology and Biochemistry 35:1079-1093.

Casper, B. B., J. F. Cahill, and R. B. Jackson. 2000. Plant competition in spatially heterogeneous environments. Pages 111-130 in M. J. Hutchings, E. A. John, and A. J. A. Stewart, editors. The ecological consequences of environmental heterogeneity. Blackwell Science, Oxford, UK.

Clements, R. P., R. Asteraki, and C. A. Jackson. 1988. A method to study the effects of chlorpyrifos on predatory ground beetles in grassland. Pages 167-174 in M. P. Greaves, B. D. Smith, and P. W. Greig-Smith, editors. Field methods for the study of environmental effects of pesticides. Proceedings of the Symposium of the British Crop Protection Council. Monograph 40. British Crop Protection Council Publications, Thornton Heath, UK.

Coupe, M. 2003. Effects of insect herbivory on herbaceous plant communities: coarse- and fine-scale examination. Thesis. University of Alberta, Edmonton, Alberta, Canada.

Dawson, L. A., S. J. Grayston, P. J. Murray, R. Cook, A. C. Gange, J. M. Ross, S. M. Pratt, E. I. Duff, and A. Treonis. 2003. Influence of pasture management (nitrogen and lime addition and insecticide treatment) on soil organisms and pasture root system dynamics in the field. Plant and Soil 255:121-130.

Day, K. J., E. A. John, and M. J. Hutchings. 2003. The effects of spatially heterogeneous nutrient supply on yield, intensity of competition and root placement patterns in Briza media and Festuca ovina. Functional Ecology 17:454-463.

De Deyn, G. B., C. E. Raaijmakers, and W. H. van der Putten. 2004. Plant community development is affected by nutrients and soil biota. Journal of Ecology 92:824-834.

Denno, R. F., C. Gratton, M. A. Peterson, G. A. Langellotto, D. L. Finke, and A. F. Huberty. 2002. Bottom-up forces mediate natural-enemy impact in a phytophagous insect community. Ecology 83:1443-1458.

Drew, M. C. 1975. Comparison of effects of a localized supply of phosphate, nitrate, ammonium and potassium on growth of seminal root system, and shoot, in barley. New Phytologist 75:479-490.

Einsmann, J. C., R. H. Jones, M. Pu, and R. J. Mitchell. 1999. Nutrient foraging traits in 10 co-occurring plant species of contrasting life forms. Journal of Ecology 87:609-619.

Eissenstat, D. M., and R. D. Yanai. 1997. The ecology of root lifespan. Advances in Ecological Research 27:1-60.

Ettema, C. H., and D. A. Wardle. 2002. Spatial soil ecology. Trends in Ecology and Evolution 17:177-183.

Farley, R. A., and A. H. Fitter. 1999. Temporal and spatial variation in soil resources in a deciduous woodland. Journal of Ecology 87:688-696.

Forschler, B. T., and W. A. Gardner. 1990. A review of the scientific literature on the biology and distribution of the genus Phyllophaga (Coleoptera, Scarabaeidae) in the southeastern United-States. Journal of Entomological Science 25:628-651. 
Frampton, G. K. 1999. Spatial variation in non-target effects of the insecticides chlorpyrifos, cypermethrin and pirimicarb on Collembola in winter wheat. Pesticide Science 55: 875-886.

Fransen, B., and H. De Kroon. 2001. Long-term disadvantages of selective root placement: root proliferation and shoot biomass of two perennial grass species in a 2-year experiment. Journal of Ecology 89:711-722.

Fransen, B., H. de Kroon, and F. Berendse. 2001. Soil nutrient heterogeneity alters competition between two perennial grass species. Ecology 82:2534-2546.

Fretwell, S. D. 1987. Food-chain dynamics-the central theory of ecology. Oikos 50:291-301.

Gaudinski, J. B., S. E. Trumbore, E. A. Davidson, A. C. Cook, D. Markewitz, and D. D. Richter. 2001. The age of fineroot carbon in three forests of the eastern United States measured by radiocarbon. Oecologia 129:420-429.

Graham, J. H. 1995. Root regeneration and tolerance of citrus rootstocks to root rot caused by Phytophthora nicotianae. Phytopathology 85:111-117.

Hairston, N. G., F. E. Smith, and L. B. Slobodkin. 1960. Community structure, population control, and competition. American Naturalist 94:421-425.

Hargrove, W. W., D. A. Crossley, Jr., and T. R. Seastedt. 1984. Shifts in insect herbivory in the canopy of black locust, Robinia pseudoacacia, after fertilization. Oikos 43:322-328.

Hendrix, S. D., V. K. Brown, and A. C. Gange. 1988. Effects of insect herbivory on early plant succession-comparison of an English site and an American site. Biological Journal of the Linnean Society 35:205-216.

Hodge, A. 2004. The plastic root: root responses to heterogeneous supplies of nutrients. New Phytologist 162:9-24.

Hogberg, P., A. Nordgren, N. Buchmann, A. F. S. Taylor, A. Ekblad, M. N. Hogberg, G. Nyberg, M. Ottosson-Lofvenius, and D. J. Read. 2001. Large-scale forest girdling shows that current photosynthesis drives soil respiration. Nature 411:789-792.

Hunter, M. D. 2001. Out of sight, out of mind: the impacts of root-feeding insects in natural and managed systems. Agricultural and Forest Entomology 3:3-9.

Hunter, M. D., T. Ohgushi, and P. W. Price, editors. 1992. Effects of resource distribution on animal-plant interactions. Academic Press, San Diego, California, USA.

Hunter, M. D., and P. W. Price. 1992. Playing chutes and ladders: heterogeneity and the relative roles of bottom-up and top-down forces in natural communities. Ecology $\mathbf{7 3}$ : 724-732.

Hutchings, M. J., E. A. John, and D. K. Wijesinghe. 2003. Toward understanding the consequences of soil heterogeneity for plant populations and communities. Ecology 84 2322-2334.

Jackson, R. B., H. A. Mooney, and E. D. Schulze. 1997. A global budget for fine root biomass, surface area, and nutrient contents. Proceedings of the National Academy of Sciences, USA 94:7362-7366.

Jones, O. T., and T. H. Coaker. 1977. Oriented responses of carrot fly larvae, Psila rosae, to plant odors, carbon-dioxide and carrot root volatiles. Physiological Entomology 2:189197.

Lura, C. L., and P. E. Nyren. 1992. Some effects of a white grub infestation on northern mixed-grass prairie. Journal of Range Management 45:352-354.

Matamala, R., M. A. Gonzalez-Meler, J. D. Jastrow, R. J. Norby, and W. H. Schlesinger. 2003. Impacts of fine root turnover on forest NPP and soil C sequestration potential. Science 302:1385-1387.

Matson, P. A., and M. D. Hunter. 1992. The relative contributions of top-down and bottom-up forces in population and community ecology. Ecology 73:723.
Michereff-Filho, M., R. N. C. Guedes, T. M. C. Della-Lucia, M. F. F. Michereff, and I. Cruz. 2004. Non-target impact of chlorpyrifos on soil arthropods associated with no-tillage cornfields in Brazil. International Journal of Pest Management 50:91-99.

Moore, J. C., K. McCann, H. Setälä, and P. C. de Ruiter. 2003. Top-down is bottom-up: does predation in the rhizosphere regulate aboveground dynamics? Ecology 84: 846-857.

Pereira, J. L., A. A. da Silva, M. C. Picanco, E. C. de Barros, and A. Jakelaitis. 2005. Effects of herbicide and insecticide interaction on soil entomofauna under maize crop. Journal of Environmental Science and Health 40:45-54.

Pregitzer, K. S. 2002. Fine roots of trees-a new perspective. New Phytologist 154:267-273.

Preisser, E. L. 2003. Field evidence for a rapidly cascading underground food web. Ecology 84:869-874.

Rajaniemi, T. K., and H. L. Reynolds. 2004. Root foraging for patchy resources in eight herbaceous plant species. Oecologia 141:519-525.

Robinson, D. 1994. The responses of plants to nonuniform supplies of nutrients. New Phytologist 127:635-674.

Robinson, D., A. Hodge, B. S. Griffiths, and A. H. Fitter. 1999. Plant root proliferation in nitrogen-rich patches confers competitive advantage. Proceedings of the Royal Society of London Series B, Biological Sciences 266:431435.

Rogers, V. A. 1990. Soil survey of Savannah River Plant area, parts of Aiken, Barnwell, and Allendale counties, South Carolina. Soil Conservation Service, USDA, Washington, D.C., USA.

Smolik, J. D., and J. L. Dodd. 1983. Effect of water and nitrogen, and grazing on nematodes in a shortgrass prairie. Journal of Range Management 36:744-748.

Stehr, F. W. 1987. Immature insects. Volume 2. Kendall-Hunt, Dubuque, Iowa, USA.

Stevens, G. N., R. H. Jones, and R. J. Mitchell. 2002. Rapid fine root disappearance in a pine woodland: a substantial carbon flux. Canadian Journal of Forest Research-Revue Canadienne de Recherche Forestiere 32:2225-2230.

Strong, D. R., H. K. Kaya, A. V. Whipple, A. L. Child, S. Kraig, M. Bondonno, K. Dyer, and J. L. Maron. 1996. Entomopathogenic nematodes: natural enemies of rootfeeding caterpillars on bush lupine. Oecologia 108:167173.

Tierney, G. L., and T. J. Fahey. 2002. Fine root turnover in a northern hardwood forest: a direct comparison of the radiocarbon and minirhizotron methods. Canadian Journal of Forest Research-Revue Canadienne de Recherche Forestiere 32:1692-1697.

Todd, T. C. 1997. Effects of management practices on nematode community structure in tallgrass prairie. Applied Soil Ecology 3:235-246.

Trumbore, S. E., and J. B. Gaudinski. 2003. The secret lives of roots. Science 302:1344-1345.

Ueckert, D. N. 1979. Impact of a white grub (Phyllophaga crinita) on a shortgrass community and evaluation of selected rehabilitation practices. Journal of Range Management 32:445-448.

USDA. 2001. Agricultural management effects on earthworm populations. Soil Quality Institute Technical Note Number 11. Natural Resources Conservation Service, USDA, Auburn, Alabama, USA.

Vittum, P. J., M. G. Villani, and H. Tashiro. 1999. Turfgrass insects of the United States and Canada. Second edition. Cornell University Press, Ithaca, New York, USA.

Wang, Y., R. L. Crocker, L. T. Wilson, G. Smart, X. Wei, W. T. Nailon, Jr., and P. P. Cobb. 2001. Effect of nematode and fungal treatments on nontarget turfgrass-inhabiting ar- 
thropod and nematode populations. Environmental Entomology 30:196-203.

Wells, C. E., D. M. Glenn, and D. M. Eissenstat. 2002. Soil insects alter fine root demography in peach (Prunus persica). Plant, Cell and Environment 25:431-439.
Wijesinghe, D. K., E. A. John, S. Beurskens, and M. J. Hutchings. 2001. Root system size and precision in nutrient foraging: responses to spatial pattern of nutrient supply in six herbaceous species. Journal of Ecology 89: 972-983.

\section{APPENDIX A}

ANOVA results showing plant responses to greenhouse application of soil insecticide (Ecological Archives E087-034-A1).

\section{APPENDIX B}

ANOVA results showing root responses to ingrowth core treatments (Ecological Archives E087-034-A2). 